\title{
Author Correction: Targeting sphingolipid metabolism as an approach for combination therapies in haematological malignancies
}

\author{
Alexander C. Lewis, Craig T. Wallington-Beddoe, Jason A. Powell and Stuart M. Pitson (1)
}

Correction to: Cell Death Discovery

https://doi.org/10.1038/s41420-018-0075-0

published online 28 June 2018

Since online publication of this article, the authors noticed errors in the labelling of some of the arrows in
Fig. 1, which shows a schematic of the sphingolipid pathway. The corrected image is provided below. The authors apologise for any inconvenience caused.

Published online: 18 June 2021 


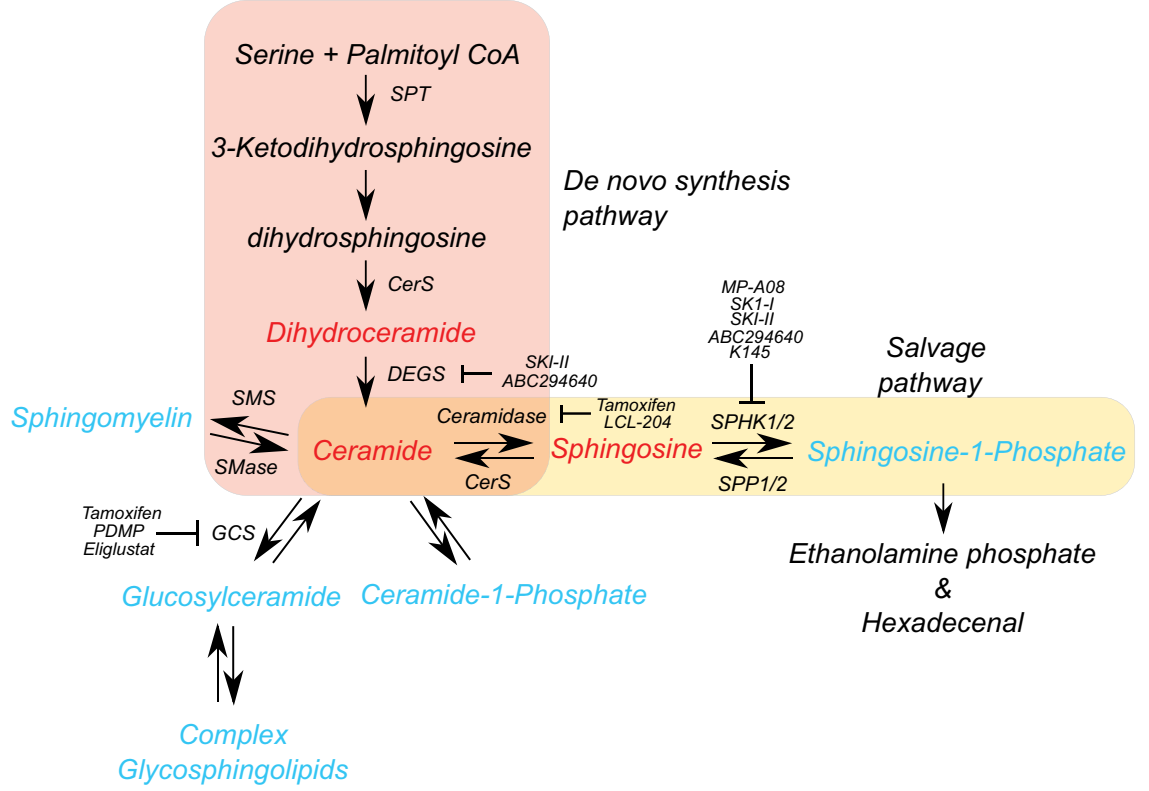

Fig. 1. 